\title{
Repetitive operation of three-phase superconducting fault current limiter in a model power system
}

\section{AUTHOR(S):}

Shirai, Y; Mochida, A; Morimoto, T; Shiotsu, M; Oide, T; Chiba, M; Nitta, T

\section{CITATION:}

Shirai, Y ... [et al]. Repetitive operation of three-phase superconducting fault current limiter in a model power system. IEEE TRANSACTIONS ON APPLIED SUPERCONDUCTIVITY 2005, 15(2): 2110-2113

\section{ISSUE DATE:}

2005-06

URL:

http://hdl.handle.net/2433/50267

\section{RIGHT:}

(c)2005 IEEE. Personal use of this material is permitted. However, permission to reprint/republish this material for advertising or promotional purposes or for creating new collective works for resale or redistribution to servers or lists, or to reuse any copyrighted component of this work in other works must be obtained from the IEEE. 


\title{
Repetitive Operation of Three-Phase Superconducting Fault Current Limiter in a Model Power System
}

\author{
Y. Shirai, Member, IEEE, A. Mochida, T. Morimoto, M. Shiotsu, T. Oide, M. Chiba, and T. Nitta, Member, IEEE
}

\begin{abstract}
Superconducting fault current limiters (SCFCLs) are expected to improve reliability and stability of power systems. To introduce an SCFCL to power systems, the repetitive operation at the severe continuous faults is one of the important function. The recovery time of the proposed 3-phase FCL was confirmed experimentally to be sufficiently short for the repetitive operation. This paper shows the experimental results and discussion on the repetitive current limiting operation of the 3-phase SCFCL, which was demonstrated in a model power system. The test condition was that the fault line is open at the fault within $100 \mathrm{~ms}$ and is re-closed within $930 \mathrm{~ms}$, but the fault is not cleared during the interval while the fault line is open. It was confirmed that the SCFCL started to limit the fault current immediate after the fault and recover to the stand-by mode during the interval, and limited the fault current again at the re-closure without any degradation of the trigger current level and the limiting impedance.
\end{abstract}

Index Terms-Fault current limiter, power system, recovery time, repetitive fault, repetitive operation.

$\mathbf{S}$ UPERCONDUCTING FAULT CURRENT LIMITERS (SCFCLs) of various types were proposed and have been studied, for example [1]-[4]. They are expected to improve reliability of power systems. However, there are few investigations from the viewpoint that the FCL is one of the power system apparatus. It is important to study the power system characteristics of the FCL. We proposed and fabricated a trial three-phase SCFCL with adjustable trigger current level to study the features of the SCFCL in a small model power system in our laboratory [5]. Specification of SCFCLs, such as trigger current level, recovery characteristic and limiting impedance, must be considered precisely, introducing SCFCLs to power system. The SCFCL consists of two LTC superconducting coils coupled co-axially. Inner (primary) coil will be connected to a power line. Outer (secondary) coil is short-circuited. Therefore, the magnetic flux is cancelled and the reactance of the FCL is small. Super/Normal transition at a fault occurs only in the secondary coil. The flux due to the primary coil appears and the fault current is limited by the inductance of the primary coil. In the former experiments, it was confirmed that the trial SCFCLs can recover from the current limiting mode to the stand-by

Manuscript received October 4, 2004. This work was supported in part by the Japan Society for the Promotion of Science under the 21st COE Project E11 by MEXT, no. 14219201, Japan.

Y. Shirai, A. Mochida, T. Morimoto, and M. Shiotsu are with the Department of Energy Science and Technology, Kyoto University, Kyoto 606-8501, Japan (e-mail: shirai@energy.kyoto-u.ac.jp; mochida@ pe.energy.kyoto-u.ac.jp; mori moto@pe.energy.kyoto-u.ac.jp; shiotsu@energy.kyoto-u.ac.jp).

T. Oide, M. Chiba, and T. Nitta are with the Department of Electrical Engineering, the University of Tokyo, Tokyo 113-8656, Japan (e-mail: oide@ asc.t.utokyo.ac.jp; chiba@asc.t.u-tokyo.ac.jp; nitta@asc.t.u-tokyo.ac.jp).

Digital Object Identifier 10.1109/TASC.2005.849464

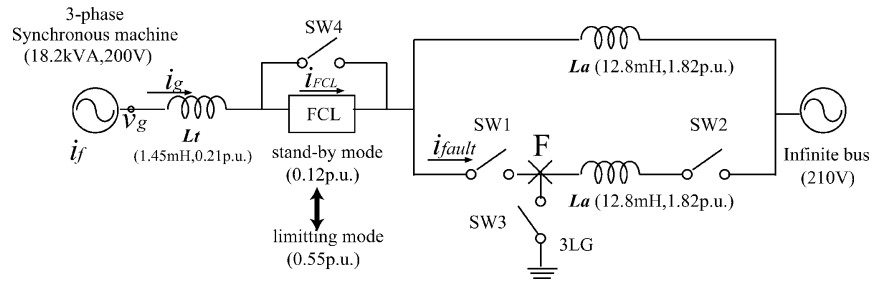

Fig. 1. Test model power system in a laboratory: small synchronous generator with SCFCLs in series and an artificial transmission line system.

mode only by short-circuited in a short time, less than $500 \mathrm{~ms}$ [6]. That is, the short-circuit of SCFCLs means that the current by-passes the SCFCLs.

In this paper, the repetitive operation of the SCFCL at the severe continuous faults was studied experimentally by use of the proposed test SCFCL of 3-phase and a small model power system in a laboratory. The relay sequence including SCFCL was proposed. The SCFCL is short-circuited to recover to the stand-by mode for a short period within the standard isolation time of the fault line in Japan, which was set $830 \mathrm{~ms}$ in the experiments. The generator power can flow continuously during the sequence. The trigger current and limiting characteristics of the SCFCL at the first and the second current limiting operation with the continuous fault were investigated.

\section{EXPERIMENTAL SYSTEM AND A SCFCL}

\section{A. Test Model Power System}

Fig. 1 shows an experimental model power system. A 3-phase synchronous generator is connected to an infinite bus $(210 \mathrm{~V}$ commercial power line) through parallel artificial transmission lines. The inductance of each line is $12.8 \mathrm{mH}(1.82 \mathrm{p} . \mathrm{u})$. The lower line (fault line) has SW3 in parallel for simulated fault and circuit breakers (SW1 and SW2) in series. The rating of the generator is $18.26 \mathrm{kVA}$, voltage is $200 \mathrm{~V}$, current is $52.5 \mathrm{~A}$, field current is $19.2 \mathrm{~A}$, rotating speed is $1500 \mathrm{rpm}, 4$-poles, $50 \mathrm{~Hz}$. The field current is supplied by a constant voltage source. The generator is installed through the three-phase SCFCL to the end of parallel line. The switch SW4 connected in parallel to SCFCLs is closed to short-circuit the SCFCL for recovery. All switches are magnetically controlled and operated at the same time in three phases.

The initial conditions of tests are as follows; the field voltage is $12.69 \mathrm{~V}$, the field current is $20.0 \mathrm{~A}$, the terminal voltage is $201.4 \mathrm{~V}$ and the output power is $4.1 \mathrm{~kW}$. The generator current $i_{g}$, voltage $v_{g}$, the field current $i_{f}$, the fault line current $i_{\text {fault }}$, the voltage $v_{F C L}$ across the FCL and the FCL current $i_{F C L}$ were measured. 


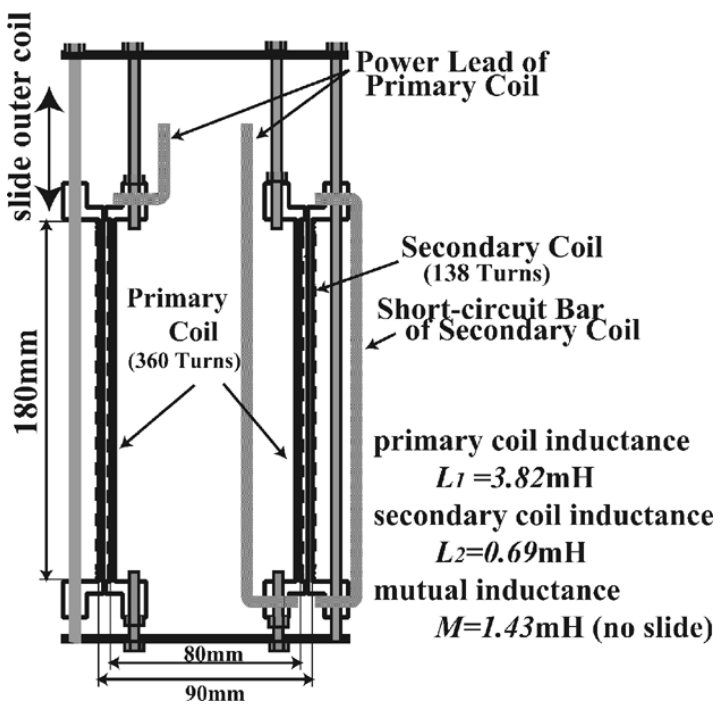

Fig. 2. Test superconducting fault current limiter with adjustable trigger current level (one of 3-phase SCFCL).

\section{B. Test SCFCLs of Three Phase}

The test SCFCL unit for three-phase operation was designed and made [5]. It contains three SCFCLs of transformer type in one cryostat. The schematic figure of the SCFCL for one-phase is shown in Fig. 2. The SCFCL consists of two superconducting coils (NbTi wire for AC use) coupled co-axially. The inner (primary) coil will be connected to a power line. The outer (secondary) coil is short-circuited. The primary coil can be slided with small slide distance in order to calibrate the trigger current level [3]. The trigger current levels of three SCFCLs for each phase were adjusted to be the same value (89.4 Arms) by calibrating the slide distances.

\section{Recovery Time From Current Limiting to Stand-By Mode of Test SCFCL}

It was already reported that the recovery time of the test SCFCL is less than $500 \mathrm{~ms}$ [7]. The recovery time means required zero-current time for SCFCL to recover from current limiting mode to stand-by mode. And it decreases to about $50 \mathrm{~ms}$ as the fault time becomes longer. The fault time means the duration time of current limiting mode of the SCFCL. This is because only a part of the wire turns to the normal state and the temperature profile along the wire has mountain shape at the beginning of current limiting. But it changes to flat shape with time, where the secondary wire current is minimum propagation current. Therefore the FCL can recover with short zero-current time of about $50 \mathrm{~ms}$. It was confirmed that the recovery operation can be achieved not only by isolating the SCFCLs from the line but also by short-circuiting them (Fig. 3) [6].

\section{Test Switching Sequence}

According to the recovery characteristics of the test SCFCLs, the test switching sequence of the current limiting tests for the repetitive faults as shown in Fig. 4.

1. At first, the SW1 and SW2 are closed and output power of the generator flows through double transmission lines.

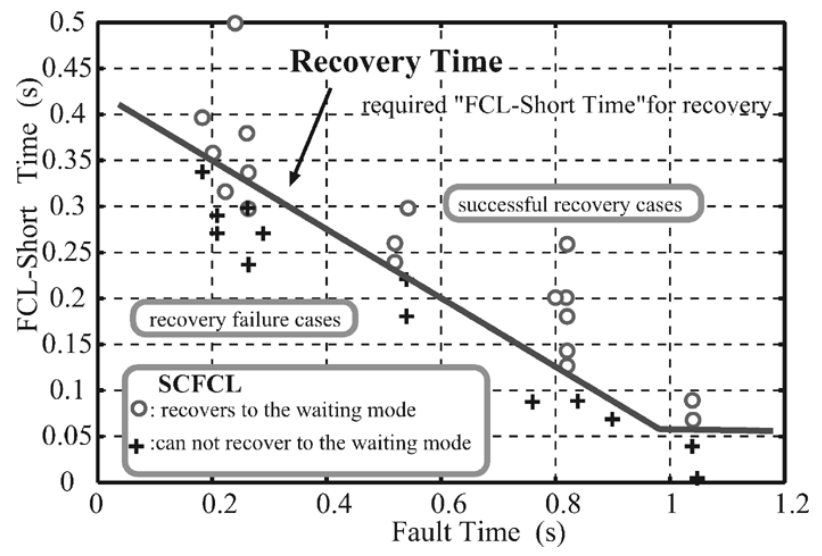

Fig. 3. Required short-circuiting time of the test SCFCL for successful recovery as a function of fault time, which is current limiting operation time of the SCFCL [6].

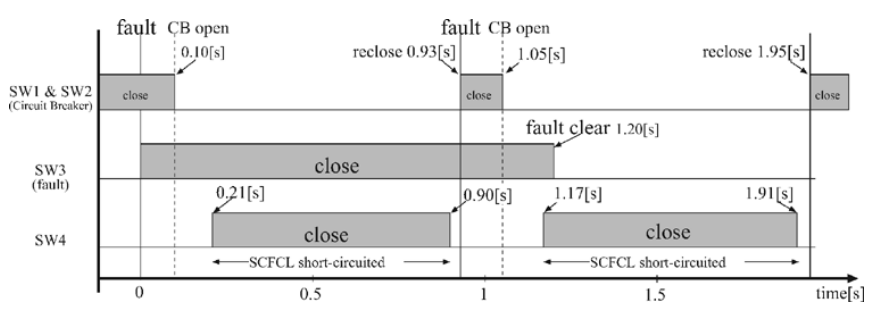

Fig. 4. Switching sequence for the repetitive operation test of SCFCLs.

2. At a certain time ( $0 \mathrm{~s}$ as indicated in Fig. 4$)$, the SW3 is closed to simulate a 3 -phase ground fault (3LG). The SCFCL will start to limit the fault current immediately after the fault.

3. The circuit breaker (CB) SW1 and SW2 of the fault line open to isolate the fault point after $100 \mathrm{~ms}$ from the initiation of the fault.

4. Then after $110 \mathrm{~ms}$ from the CB-open, the SCFCL is shortcircuited for $690 \mathrm{~ms}$ to recover to the stand-by mode.

5. The fault line is re-closed after $830 \mathrm{~ms}$ from the $\mathrm{CB}$-open. However the fault has still continued, that is the SW3 is still closed. If the SCFCLs recover to the stand-by mode completely, they will start again to limit the fault current immediately after the re-closure.

6. During the second isolation of the fault line, the fault is cleared and the SCFCLs recover to the stand-by mode again.

7. At last, the fault line is re-closed again and the system returned to the initial conditions.

\section{EXPERIMENTAL RESULTS AND DISCUSSION}

\section{A. Experimental Results}

Fig. 5 shows one of the experimental results of the voltages and the currents at the 3 -phase short fault with the SCFCLs. The figure shows the field current $i_{f}$, the generator terminal voltage $v_{g}$, the generator armature current $i_{g}$, the SCFCL current $i_{F C L}$ and the fault line current $i_{\text {fault }}$ from the top to the bottom. These data are of u-phase except the field current. 


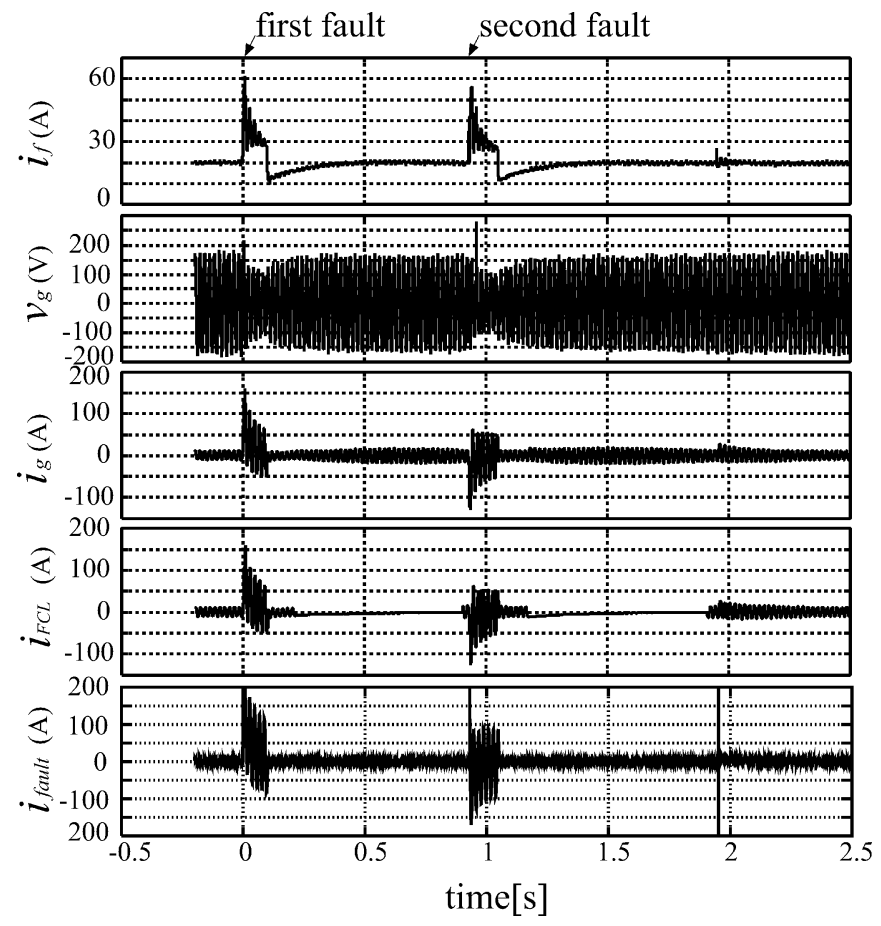

Fig. 5. Experimental results of the repetitive current limiting operation of the SCFCL at the continuous fault.

The 3-phase line ground (3LG) fault occurred at point $\mathrm{F}$ at $0 \mathrm{~s}$. The transient response appeared in every current. the FCL current exceeded the trigger current and began to limit the fault current immediately. The impedance of the FCL became 0.55 p.u. $(1.2 \Omega)$. The generator terminal voltage was kept above about $100 \mathrm{~V}$. After $100 \mathrm{~ms}$ from the fault, the fault line was isolated by the SW1, 2 and the fault line current was shut to zero. However, the generator power continued to flow through the safe line to the infinite bus. After $110 \mathrm{~ms}$ from the isolation of the fault line, the FCL was short-circuited for $690 \mathrm{~ms}$ to recover from the current limiting to the stand-by mode. The generator current continued to flow through the shunt-line (SW4). The disturbance applied to the generator was reduced by the SCFCL and the proposed switch sequence.

The fault line re-closed at $910 \mathrm{~ms}$ (the isolation time is $830 \mathrm{~ms})$. But the fault still continued and the fault current appeared again. Since the current phase at the re-closure (the second fault initiation) was different from that at the first fault, the DC component of the transient current was negative. The SCFCL began to limit the second fault current in the same manner. It had already recovered to the stand-by mode during the first short-circuited time. The fault was cleared during the second isolation of the fault line and the system returned to the initial condition after the second re-closure of the fault line at $1.95 \mathrm{~s}$.

\section{B. Current Limiting Characteristics at the 1st and 2nd Faults}

Fig. 6 shows the enlarged waveforms of the experimental results around the 1st fault in Fig. 6(a) and 2nd fault in Fig. 6(b), respectively, with SCFCL (left) and without SCFCL (right). In order to compare the results at the two faults, the currents and
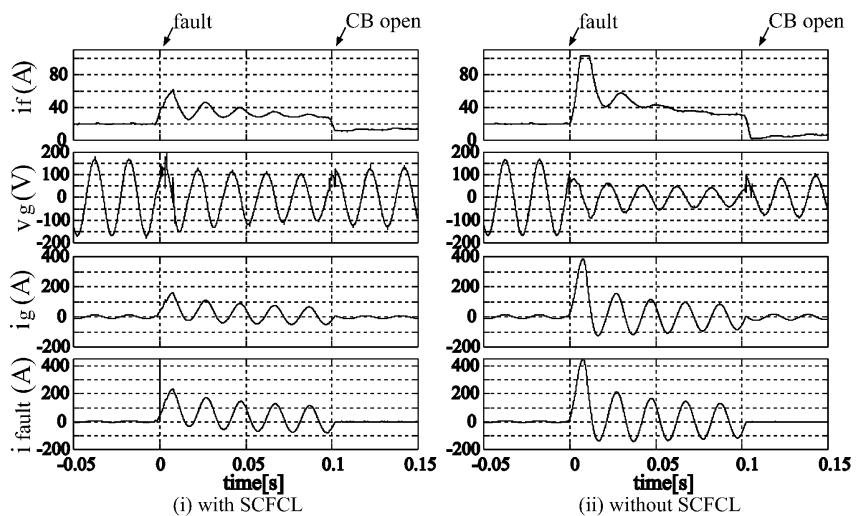

(a) first fault (u)

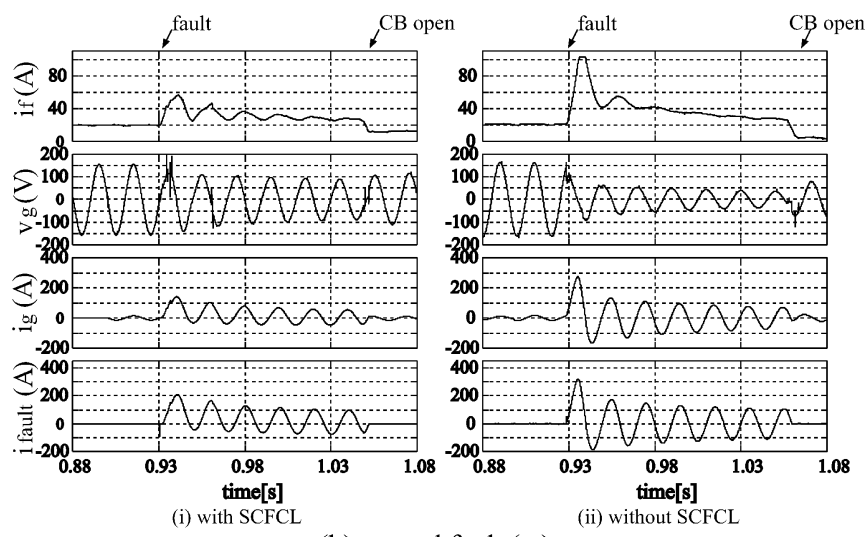

(b) second fault $(\mathrm{w})$

Fig. 6. Enlarged waveforms of currents and voltage around the first fault (a) and around the second fault (b) with and without SCFCL.

voltages of w-phase are shown for the 2nd fault, whose fault phase was similar to that of u-phase at the 1st fault.

According to the 1st fault, the SCFCLs for 3-phases were all activated to limit the fault current. The fault line current is sum of the fault current from the generator and that from the infinite bus through the safe line and had 452.3 A peak (4.96 p.u. peak) without SCFCL. It was reduced to 233.9 A peak (2.56 p.u. peak) with SCFCL. The generator armature current had 386 A peak (4.23 p.u. peak) without SCFCL and was reduced to $158.4 \mathrm{~A}$ peak (1.73 p.u. peak) with SCFCL. The field current exceeded $100 \mathrm{~A}$ (5.2 p.u.) without SCFCL and was suppressed to $60.5 \mathrm{~A}$ (3.15 p.u.) with SCFCLs. The SCFCL of u-phase started to limit the fault current at $112.4 \mathrm{~A}$ (the instantaneous trigger current level). The generator terminal voltage during the fault was kept larger than 107.3 Vminimum peak with SCFCL current limiting operation.

As for the 2nd fault, the degradation of the trigger current level of the SCFCLs, for example, is concerned. If the heat generated at the 1st current limiting operation of the SCFCL is not completely removed during the short-circuited time of $690 \mathrm{~ms}$, the trigger current level of the SCFCL for the repetitive fault may become lower. In the experimental results, however, the SCFCL successfully limited the second fault current with the trigger current level of 117.2 A, which was almost same with that at the first fault $(112.4 \mathrm{~A})$. No degradation of the trigger current level was observed.

The waveforms of the generator current, voltage and the field current were similar to those at the first fault. The peak value of 
TABLE I

Peak Value of CurRents and Voltage at the Continuous Fault WITH/WITHOUT SCFCL

\begin{tabular}{c|c|c|c|c}
\hline \hline \multirow{2}{*}{ Peak Value } & \multicolumn{2}{|c|}{ 1ST FAULT } & \multicolumn{2}{c}{ 2ND FAULT } \\
\cline { 2 - 5 } & WITH FCL & $\begin{array}{c}\text { WITHOUT } \\
\text { FCL }\end{array}$ & WitH FCL & $\begin{array}{c}\text { WiTHOUT } \\
\text { FCL }\end{array}$ \\
\hline $\begin{array}{c}\text { Field } \\
\text { current(A) }\end{array}$ & 60.5 & $102.4 \sim$ & 56.1 & $102.4 \sim$ \\
$\begin{array}{c}\text { Terminal } \\
\text { voltage(V) }\end{array}$ & 107.3 & 42.0 & 89.8 & 32.7 \\
$\begin{array}{c}\text { Armature } \\
\text { current(A) }\end{array}$ & 158.4 & 386.0 & 140.6 & 274.8 \\
$\begin{array}{c}\text { Fault line } \\
\text { current (A) } \\
\text { Trigger }\end{array}$ & 233.9 & 452.3 & 210.2 & 321.3 \\
current (A) & 112.4 & --- & 117.2 & --- \\
\hline \hline
\end{tabular}

each currents and voltage at each fault are shown in Table I. The generator was protected from the repetitive faults. The shortcircuit capacity of the circuit breaker (SW1) is reduced to almost half of that without SCFCL.

Moreover, two sets of the test sequence were applied to the experimental system in series. The current limiting operation of the SCFCL occurred 4 times repetitively at last. The trigger current level of each faults was 114.4, 120.6, 112.0, 116.8 A, respectively. No degradation of the trigger current level and the limiting impedance was observed at any fault.

\section{CONCLUSION}

The functions of the SCFCLs to protect generators form the repetitive fault were studied and examined experimentally by use of a small synchronous test generator with a test three-phase SCFCL unit and an artificial transmission line. The following results were obtained.
The SCFCLs of each phase started to limit the fault current immediately after the each phase current reached the trigger current level repetitively at the continuous faults.

The large transient current of the armature winding and the field winding of the generator at the 3-phase-line-ground fault were limited to almost half of those without SCFCL. The generator was protected successfully from the excessive current at the fault. The short-circuit capacity of the Circuit Breaker (SW1) is reduced to almost half of that without SCFCL.

In general, a FCL should meet the repetitive faults as shown in this paper. It was confirmed that test SCFCL can recover to the stand-by mode by shunting the current for shorter time compared with the standard circuit breaker re-closure time in Japan. The SCFCL starts to limit the fault current immediate after the fault and recovers to the stand-by mode during the interval, and limited the fault current again at the re-closure without any degradation of the trigger current level and the limiting impedance.

\section{REFERENCES}

[1] E. Leung et al., "Design \& development of a $15 \mathrm{kV}, 20 \mathrm{kA}$ HTS fault current limiter," IEEE Trans. Appl. Supercond., vol. 10, no. 1, pp. 832-835 Mar. 2000.

[2] B. Gromoll et al., "Resistive fault current limiters with YBCO films-100 kVA functional model," IEEE Trans. Appl. Supercond., vol. 9, no. 2, pp. 656-659, Jun. 1999.

[3] K. Fujikawa et al., "Experimental study on adjustability of super-conducting fault current limiter with adjustable trigger current level," IEEE Trans. Appl. Supercond., vol. 9, no. 2, pp. 1351-1354, Jun. 1999.

[4] T. Hara et al., "Development of a new $6.6 \mathrm{kV} / 1500$ A class superconducting fault current limiter for electric power systems," IEEE Trans. Power Del., vol. 8, no. 1, pp. 182-192, Jan. 1993.

[5] H. Hatta et al., "Experimental study on sudden-short-circuit characteristic of synchronous generator with SCFCL," IEEE Trans. Appl. Supercond., vol. 11, no. 1, pp. 2343-2346, Mar. 2001.

[6] Y. Shirai et al., "A proposal of new operating procedure of transformer type fault current limiter," IEEE Trans. Appl. Supercond., vol. 12, no. 1, pp. 885-889, Mar. 2002.

[7] - "Recovery process of a transformer type superconducting fault current limiter," IEEE Trans. Appl. Supercond., vol. 12, no. 1, pp. 880-883, Mar. 2002. 